\title{
Impact of magnetic field on electrochemistry of heavy metals removal processes by duckweed (lemna)
}

\author{
Natalia Politaeva ${ }^{1, *}$, Rostislav Rusinov 1 , Yurii Karyakin ${ }^{1}$, Boris Fokin ${ }^{1}$, and Konstantin \\ Grigoryev $^{1}$ \\ ${ }^{1}$ Peter the Great St.Petersburg Polytechnic University, Polytechnicheskaya, 29, St. Petersburg, \\ 195251, Russia
}

\begin{abstract}
The influence of various factors (initial concentration of the solution, contact time of the biosorbent with the solution, and the action of a constant parallel magnetic field of intensity $4 \mathrm{kA} / \mathrm{m}(50$ Oe $))$ on the processes of extraction of heavy metal ions $(\mathrm{Zn}, \mathrm{Cd}, \mathrm{Cu})$ from wastewater with the help of bioelectrochemical reactor - duckweed is in the focus of this study.
\end{abstract}

\section{Introduction}

The main sources of pollution of natural waters with heavy metals (HM) are wastewater (WW) of galvanic shops, mining enterprises, ferrous and non-ferrous metallurgy, machinebuilding plants. Most of the known methods of sewage purification are expensive, difficult to perform, they focus on imported equipment and scarce reagents [1-9]. Recently industrially developed countries started to introduce the technology of clearing wastewaters, contaminated with heavy metals, with the help of higher water plants (HWP), called phytoremediation. Plant cell, which is a natural bioelectrochemical membrane reactor, is efficiently able to extract and dispose HM. At the same time, no by-products accumulate in the environment, and it is possible to create low-waste, non-reagent technologies for extracting HM from wastewater and rinsing water. Establishing the regularities in the processes of electrochemical sorption will make it possible to approach purposefully the choice of a biosorbent for qualitative selective treatment of reservoirs from HM. Such research is relevant and has a great scientific and practical significance.

According to experts up to date phytoremediation is the most environmentally friendly and cheap way of water purification and disinfection, since it does not require additional energy costs, complex equipment, chemical reagents. Of course, this is a long process, but the cost of phytoremediation usually does not exceed $\sim 20 \%$ of the cost of alternative technologies. In this regard, in recent years, both abroad and in our country, intensive work is under way of using various plants in the fight against anthropogenic eutrophication of water bodies. Recently the process of phytoremediation has become quite widely spread [10-13]. However, insufficient attention has been paid to solving the problem of increasing the speed

${ }^{*}$ Corresponding author: politaevana1971@gmail.com 
and efficiency of contaminated water cleaning. The mechanism of the process is not fully understood and described. Many authors simply state the very fact of reducing pollutants from the contact of HWP with sewage water. In our opinion, it is necessary to study in more detail the influence of physical influences (magnetic, electric fields, infrared, ultraviolet radiation, etc.) on the state of plants and the processes taking place with their participation.

The effect of the magnetic field (MF) and other factors on the behavior of plants is poorly understood, and research in this direction can clarify the mechanism of its action. Some studies [14-19] were carried out exploring the affect of constant magnetic field on the movement of protoplasm of plant cells and on the growth characteristics of the cell. It is established $[16,17]$ that in the perpendicular magnetic field the movement of protoplasm and cell growth accelerates, and in a strong parallel field it slows down by $15-20 \%$. The growth enhancement reaction persists with an increase in the field strength to $60 \mathrm{Oe}$, but at 4000 and 12000 Oe it already manifests itself as a factor inhibiting the growth process [20-22]. The results of the action of a weak $(20 \mathrm{Oe})$ constant magnetic field on the motion of protoplasm allowed us to establish the significant effect of the field of such a force on the movement of protoplasm [18]. Savostin's works $[15,17]$ on the influence of a constant magnetic field on the movement of protoplasm and plant growth were the material that greatly helped the experimenters in the field of magneto biology to check and further develop his ideas. At this stage it is established that the effect of the magnetic field can manifest either as a stimulant or as a retarder for the development of cells and the root system of plants. In this case, the course of these processes is influenced not only by the force, but also by the strength and direction of the magnetic field [14-16]. In a perpendicular field the motion of protoplasm accelerates much more efficiently than in a parallel magnetic field.

Thus, the effect of MF on plants and on their physiological functions can appear either as a result of an influence on the genetic apparatus, for example through cell division, or as a result of direct interference with the metabolism [14]. When the magnetic field interacts with a bio object, electromagnetic disturbances have an impact, primarily on the physicochemical processes, and through them on the directionality of biochemical reactions.

The purpose of this work was to study the processes of extraction of heavy metal ions $(\mathrm{Zn}, \mathrm{Cd}, \mathrm{Cu})$ from sewage with the help of a bio-electrochemical duckwheat reactor, without and under the influence of a constant parallel magnetic field of intensity $4 \mathrm{kA} / \mathrm{m}$ (50 Oe).

\section{Experimental data}

Sulfate model solutions, $\mathrm{CuSO}_{4}, \mathrm{ZnSO}_{4}$, and $\mathrm{CdSO}_{4}$ containing various concentrations of heavy metal cations served as the objects of the study: 5 and $1 \mathrm{mg} / 1 \mathrm{of} \mathrm{Cu} 2+, \mathrm{Cd} 2+, \mathrm{Zn} 2+$. As a phytosorbent we used HWP - duckweed, zoned in the Saratov region. Analysis of the solutions for heavy metal ions was carried out by inversion Chrono voltammetry with the use of a robotic "Expertise VA-2D" complex with an "3 in 1" electrode.

The effect of the aging time of plants in copper and cadmium sulfate solutions without the influence of a magnetic field (MF) and the application of a constant parallel MF $(4 \mathrm{kA} / \mathrm{m}$ or $50 \mathrm{Oe}$ ) on the efficiency of the extraction of heavy metals from sewage was investigated. All studies were carried out at room temperature $\left(23 \pm 1^{\circ} \mathrm{C}\right)$.

Plants of the same aging period and the same weight (20 grams per liter) were planted in model solutions and, after holding them for a certain period of time (hours: 1, 24, 120, 144, $288,432,576,720)$, residual concentrations of ions of heavy metals (HM) were measured in the solutions. The concentration was determined using the method of adding a standard solution of the test metal. The essence of the method is the registration of voltammograms at the same parameters of the analyzed solution and the analyzed solution with the standard additive. The content of metal ions in the solution of the analyzed sample was calculated from the values of the analytical signals of the voltammograms relative to the peak of the 
currents of the analyzed solution taken in an amount of $20 \mathrm{ml}$ and a solution with a standard additive which was introduced into the solution in an amount of $5 \mathrm{ml}$.

Obtained data on the extraction of HM from sulfate solutions using duckweed as a sorbent without the influence of MP are presented in Fig. 1 and Table. 1.

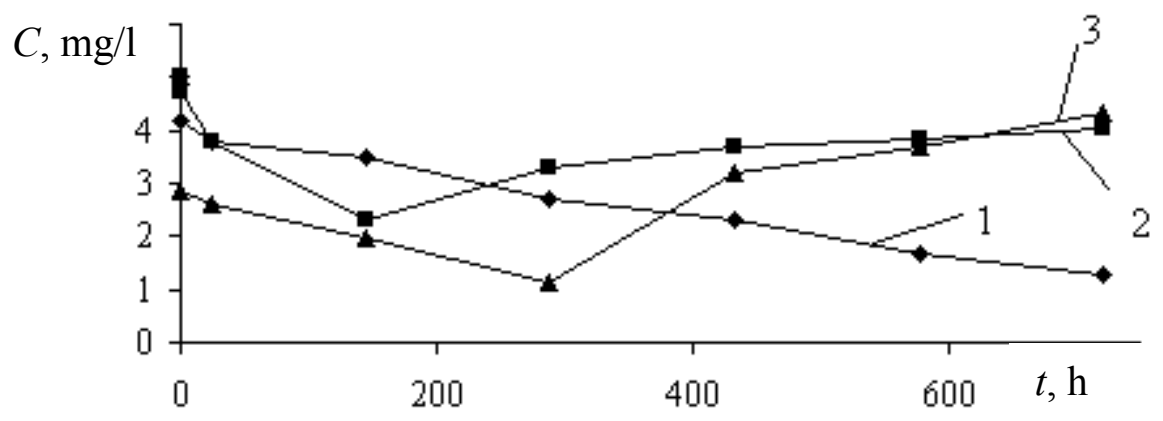

Fig. 1. The change in the concentration of copper (1), zinc (2), and cadmium (3) in time with the extraction by duckweed of HM from their sulfate solutions with an initial concentration of $5 \mathrm{mg} / \mathrm{l}$

Analysis of the data indicates that the greatest change in the initial concentration, which corresponds to the highest rate of extraction of heavy metals, is observed during the first hours of the duckweed plant in model solutions.

The dependences of the velocity variation of copper, zinc and cadmium extraction by duckweed (Fig. 1), indicate that in the initial period (approximately an hour and a day), the plant extracts the greatest amount of toxic cadmium. With the passage of time, the extraction rates of metals by duckweed are equalized (Table 1).

Table 1. The change in the mass concentration of heavy metal ions in the solution and the rate of their extraction $(\mathrm{V})$ by the duckweed depending on the residence time $(\tau)$ of the plant in the solution $(\mathrm{Cic}=5 \mathrm{mg} / \mathrm{l})$

\begin{tabular}{|c|c|c|c|c|c|c|}
\hline \multirow{2}{*}{$\underset{\text { (24 hours) }}{\tau, \mathrm{h}}$} & \multicolumn{2}{|c|}{$\mathrm{Cu}$} & \multicolumn{2}{|c|}{$\mathrm{Zn}$} & \multicolumn{2}{|c|}{$\mathrm{Cd}$} \\
\hline & $C, \mathrm{mg} / \mathrm{l}$ & $\begin{array}{c}V, \\
\mathrm{mg} / \text { hour }\end{array}$ & $C, \mathrm{mg} / \mathrm{l}$ & $\begin{array}{c}V, \\
\mathrm{mg} / \text { hour }\end{array}$ & $C, \mathrm{mg} / \mathrm{l}$ & $\begin{array}{c}V, \\
\mathrm{mg} / \text { hour }\end{array}$ \\
\hline 0 & 5.00 & - & 5.00 & - & 5.00 & - \\
\hline 1 & 4.21 & 0.790 & 4.73 & 0.270 & 2.83 & 2.17 \\
\hline $24 \quad(1)$ & 3.78 & 0.051 & 3.81 & 0.050 & 2.62 & 0.099 \\
\hline $120 \quad(5)$ & 3.62 & 0.012 & 2.53 & 0.021 & 2.07 & 0.024 \\
\hline $144 \quad(6)$ & 3.51 & 0.010 & 2.31 & 0.019 & 1.98 & 0.021 \\
\hline $288 \quad(12)$ & 2.69 & 0.008 & 3.28 & +0.006 & 1.15 & 0.013 \\
\hline 432 (18) & 2.02 & 0.007 & 3.67 & +0.003 & 3.24 & +0.004 \\
\hline $576 \quad(24)$ & 1.59 & 0.006 & 3.82 & +0.002 & 3.71 & +0.002 \\
\hline $720 \quad(30)$ & 1.30 & 0.005 & 4.02 & +0.001 & 4.31 & +0.001 \\
\hline
\end{tabular}

In the course of the experiment, we first obtained the results that indicated the ultimate accumulation, or rather, the dumping of heavy metals by plants into the solution after a certain time for each metal. So, after aging of the plants during the first ten days, the concentration of $\mathrm{Zn} 2+$ ions in the solution gradually decreased, and after 12 days, an inverse addition of zinc to the solution was observed, which indicates the discharge of a dirty excess toxic dose of zinc. A similar process for cadmium was achieved later in $\sim 18$ days. In the case of copper, no surplus metal was released during the entire experiment (30 days). During the period of discharge by plants of the accumulated excess concentration of HM, a change in 
their appearance was observed. Actively progressed degradation of duckweed material structure, water penetrated into the phytomass, the color of the plant changed from bright green (initial state) to brown color, during oppression. After further exposure to the solution the plant died.

With a decrease in the concentration of metal cations fivefold to $1 \mathrm{mg} / \mathrm{l}$, the copper, zinc and cadmium removal processes are generally similar to those described above (Fig. 2, Table 2).

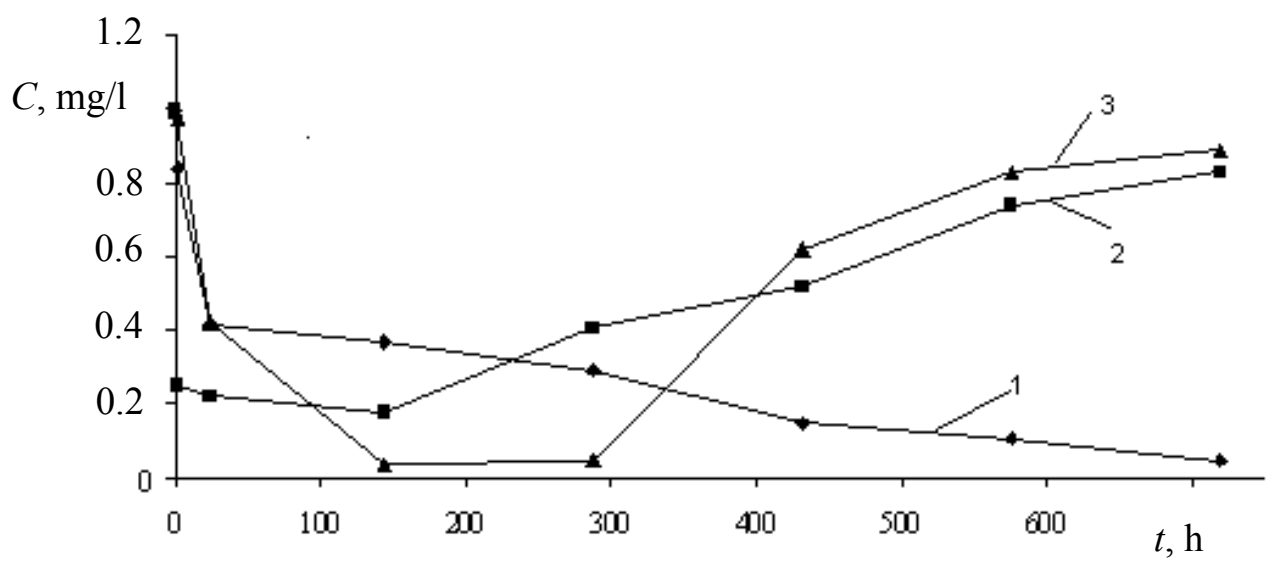

Fig. 2. The change in the concentration of copper (1), zinc (2) and cadmium (3) in time when extracted by duckweed from sulfate solutions $(1 \mathrm{mg} / \mathrm{l})$

Table 2. The change in the mass concentration of heavy metal ions in the solution and the rate of their extraction $(V)$ by duckweed depending on the time $(\tau)$ of the plant in solution

\begin{tabular}{|c|c|c|c|c|c|c|}
\hline \multirow{2}{*}{$\underset{\text { (24 hours) }}{\mathcal{\tau}, \mathrm{h}}$} & \multicolumn{2}{|c|}{$\mathrm{Cu}$} & \multicolumn{2}{|c|}{$\mathrm{Zn}$} & \multicolumn{2}{|c|}{$\mathrm{Cd}$} \\
\hline & $C, \mathrm{mg} / \mathrm{l}$ & $\begin{array}{c}V, \\
\mathrm{mg} / \text { hour }\end{array}$ & $C, \mathrm{mg} / \mathrm{l}$ & $\begin{array}{c}V, \\
\mathrm{mg} / \text { hour }\end{array}$ & $C, \mathrm{mg} / \mathrm{l}$ & $\begin{array}{c}V, \\
\mathrm{mg} / \text { hour }\end{array}$ \\
\hline 0 & 1.00 & - & 1.00 & - & 1.00 & - \\
\hline 1 & 0.84 & 0.060 & 0.65 & 0.350 & 0.87 & 0.130 \\
\hline $24 \quad(1)$ & 0.42 & 0.024 & 0.22 & 0.033 & 0.42 & 0.024 \\
\hline $120 \quad(5)$ & 0.40 & 0.005 & 0.20 & 0.007 & 0.08 & 0.008 \\
\hline $144 \quad(6)$ & 0.37 & 0.0044 & 0.18 & 0.006 & 0.04 & 0.007 \\
\hline $288 \quad(12)$ & 0.29 & 0.0025 & 0.41 & +0.002 & 0.05 & +0.003 \\
\hline $432 \quad(18)$ & 0.15 & 0.0002 & 0.52 & +0.001 & 0.62 & +0.0009 \\
\hline $576 \quad(24)$ & 0.11 & 0.0002 & 0.74 & +0.0004 & 0.83 & +0.0002 \\
\hline $720 \quad(30)$ & 0.05 & 0.0001 & 0.83 & +0.0002 & 0.92 & +0.0001 \\
\hline
\end{tabular}

As in the case of highly concentrated solutions $(5 \mathrm{mg} / \mathrm{l})$, in solutions of $1 \mathrm{mg} / 1$ concentration the highest rate of metal removal was achieved within the first five hours. The rate of extraction of copper, zinc and cadmium decreased by 2-5 or more times. The difference is that discharge of cadmium, as well as zinc, occurred on the 12th day.

When studying the effect of magnetic field, it was found that the process of extraction of heavy metals differs from the process that takes place without the participation of magnetic field (Table 3). 
Table 3. The change in the mass concentration of heavy metal ions and the rate of their removal $(V)$, depending on the residence time $(\tau)$ of the HWP duckweed in solutions of various concentrations under the action of a constant parallel magnetic field of $4 \mathrm{kA} / \mathrm{m}$ intensity

\begin{tabular}{|c|c|c|c|c|c|c|c|c|}
\hline \multirow{2}{*}{$\begin{array}{c}\mathcal{\mathcal { T }}, \mathrm{h} \\
(24 \\
\text { hours })\end{array}$} & \multicolumn{4}{|c|}{$\mathrm{Cd}$} & \multicolumn{4}{|c|}{$\mathrm{Cu}$} \\
\hline & $\begin{array}{c}C, \\
\mathrm{mg} / \mathrm{l}\end{array}$ & $V, \mathrm{mg} /$ hour & $\begin{array}{c}\mathrm{C} \\
\mathrm{mg} / \mathrm{l}\end{array}$ & $V, \mathrm{mg} /$ hour & $\begin{array}{c}C, \\
\mathrm{mg} / \mathrm{l}\end{array}$ & $V, \mathrm{mg} /$ hour & $\begin{array}{c}C \\
\mathrm{mg} / \mathrm{l}\end{array}$ & $V, \mathrm{mg} /$ hour \\
\hline 0 & \begin{tabular}{|l|l|}
5.00 \\
\end{tabular} & - & 1.00 & - & 5.00 & & 1.00 & - \\
\hline 1 & 4.48 & 0.520 & 0.99 & 0.010 & 4.23 & 0.770 & 0.84 & 0.160 \\
\hline 3 & 3.62 & 0.462 & 0.93 & 0.023 & 4.11 & 0.297 & 0.71 & 0.097 \\
\hline 5 & 3.28 & 0.344 & 0.71 & 0.058 & 3.97 & 0.057 & 0.63 & 0.074 \\
\hline $24 \quad(1)$ & 2.64 & 0.092 & 0.58 & 0.018 & 3.83 & 0.049 & 0.48 & 0.022 \\
\hline $120(5)$ & 3.49 & 0.013 & 0.67 & 0.003 & 3.74 & 0.011 & 0.39 & 0.005 \\
\hline $144(6)$ & 3.67 & 0.009 & 0.71 & 0.0028 & 3.52 & 0.010 & 0.35 & 0.0045 \\
\hline $288(12)$ & 3.79 & 0.004 & 0.76 & 0.0008 & 2.69 & 0.008 & 0.29 & 0.0025 \\
\hline $432(18)$ & 3.95 & 0.002 & 0.80 & 0.0004 & 2.34 & 0.006 & 0.15 & 0.0020 \\
\hline $576(24)$ & 4.02 & 0.0016 & 0.81 & 0.0003 & 1.69 & 0.0057 & 0.11 & 0.0016 \\
\hline $720(30)$ & 4.68 & 0.0004 & 0.89 & 0.0002 & 1.31 & 0.0051 & 0.05 & 0.0013 \\
\hline
\end{tabular}

\section{Discussion}

The removal of copper and cadmium cations from the sulfate solutions of their salts also proceeds most efficiently in the initial period of 1-5 hours. A sufficiently high rate of metal removal is achieved up to $\sim 5$ days. The analysis of the data in Table 3 showed that the greatest change in the initial concentration of solutions during the extraction of metals by duckweed was noted for cadmium. The removal of copper occurs at lower rates than cadmium. It was also found that after about 120 hours, a reverse discharge of cadmium into the solution was observed. Maximum accumulation of HM in the plant was achieved on day 5, while without exposure to a magnetic field, at significantly later times, by $\sim 12-18$ days. For copper, as well as without the influence of MP during the entire study period (30 days), a regular decrease in the concentration of metal in the solution occurred, and, correspondingly, an increase in the accumulation of $\mathrm{Cu} 2+$ by the phytomass of the plant.

The mechanism of sorption by the plant of toxicants is carried out by the movement of dissolved substances through the ion-conducting cell of plants under the action of the chemical potential gradient and the difference of electrical potentials arising on the cell membrane. Thus, plants with their complex system are used as a kind of storage bio electrochemical systems for the sorption of water-soluble forms of heavy metals. Conducted studies showed that the size of the cation or atom of the metals and their electrical characteristics (the magnitude of the standard electrode potential) [23] do not have determining role or influence on the process of phytoremediation. However, it is known [24] that cadmium is more active than other metals displacing (replacing) calcium in living cells and tissues. It is also known that cadmium alters the activity of a large number of enzymes involved in the metabolism of nucleic acids, redox reactions and electron transport [25].

The mechanism of the action of MF can be explained as follows. The application of a magnetic field increases the permeability of the cell membrane, which increases the flow of cations into the cell from the solution, and, accordingly, reduces the time of extraction of HM by the phytomass of the plant, compared with processes proceeding without magnetic field application.

It was found that affected by MF the appearance of the plant also changed at an earlier time. So already after 3-5 days as a result of cytoplasmolysis, signs of the plant's non-viability 
appeared: blanching, decay, yellowish color, which indicated the change in the structure of the cell. On about $24-30^{\text {th }}$ day the plant died.

Thus, a parallel magnetic field of $4 \mathrm{kA} / \mathrm{m}(50 \mathrm{Oe})$ had a negative effect on the recovery of heavy metals from sulfate solutions of their salts.

\section{Conclusion}

As a result of the work done, it was found that the highest rate of HM extraction in water is achieved in the first hours of the duckweed plant placed in the solutions and depends on the nature and concentration of the metal. At this stage, the results obtained indicate that the effect of a parallel magnetic field of $4 \mathrm{kA} / \mathrm{m}(50 \mathrm{Oe})$ did not have a positive effect on the process of phytoremediation. Research in this direction must continue. Obtained experimental results correspond with the data [14], stating that under the action of highintensity fields, processes occurring in plant cells are disrupted; the content of RNA varies; the area of cell division and the zone of cell stretching changes. In general, this can lead to inhibition of plant growth processes, and, consequently, to a decrease in the rate of extraction of heavy metals (copper, cadmium) and other substances involved in the construction (production) of phytocenoses.

\section{References}

1. A. Khalil, N. Sergeevich, V. Borisova, Adsorption Science and Technology 36(5-6), 1294-1309 (2018)

2. V. Umanets, L. Kalitova, D. Kalitov, A. Chusov, E. Umanets, International Multidisciplinary Scientific GeoConference Surveying Geology and Mining Ecology Management, SGEM 1(5), 135-144 (2015)

3. Kh.V. Il'ina, N.M. Gavrilova, E.A. Bondarenko, M.Ju. Andrianova, A.N. Chusov Magazine of Civil Engineering 76(8), 241-254 (2017)

4. A.V. Chechevichkin, N.I. Vatin, V.V. Samonin, M.A. Grekov, Magazine of Civil Engineering 76(8), 201-213 (2017)

5. V. Nezdoiminov, V. Ziatina, V. Rozhkov, D. Nemova, Procedia Engineering 117(1), 1022-1027 (2015)

6. E. Simonenko, A. Gomonov, N. Rolle, L. Molodkina, Procedia Engineering 117(1), 337$344(2015)$

7. E.N. Arakcheev, V.E. Brunman, M.V. Brunman, A.N. Volkov, V.A. D’yachenko, A.V. Kochetkov, A.P. Petkova, A. P., Russian Engineering Research 36(9), 745-750 (2016)

8. M.S. Alshabab, M. Andrianova, D. Alsalloum MATEC Web of Conferences 53, 01040 (2016)

9. A. Asadpoori, C. Ankomah, A. Asadpoori, O. Derevianko, E. Shaburov, MATEC Web of Conferences 193, 02039 (2018)

10. V.V. Kravets, L.B. Buhgalter, A.P. Akolzin, B.L. Buhgalter, Ecology and industry of Russia 8, 20-23(1999)

11. V.A. Dushenkov, I.V. Raskin IV, Chemistry and Life 11, 48 - 49 (1999)

12. D.E. Salt, M. Blaylock, N.P. Kumar, V. Dushenkov, B.D. Ensley, I. Chet, I. Raskin, Biotechnology 13(5), 468-74 (1995)

13. Yu.A. Tarushkina, L.N. Olshanskaya, O.E. Mecheva, A.N. Lazutkina, Ecology and industry of Russia 5, 36-39 (2006)

14. Yu.A. Kholodov, On the mechanism of biological effect of a constant magnetic field, Moscow: Nauka (1971) 
15. P.V. Savostin, Newscast of Tomsk State University. 79(4), 207 - 231 (1928)

16. A.S. Pressman, Electromagnetic fields and life. Moscow: Nauka. Russian (1968)

17. P.V. Savostin, Writings of Moscow House of Scientists 1, 111-121 (1937)

18. E.J. Ambrose, Endeavor 24(1), 215-222 (1965)

19. P.V. Savostin, Newscast of Tomsk State University 79(4), 261 - 271 (1928)

20. A.V. Krylov, G.A. Tarakanova, Physiology of plants 7, $191-197$ (1960)

21. V.Yu. Strelkova, Electronic processing of materials, 6, $74-78$ (1967)

22. G.A. Tarakanova, Physiology of Plants 3, $450-457$ (1968)

23. V.A. Rabinovich, Z.Ya. Khavin, Brief chemical reference book. Leningrad: Chemistry. (1978)

24. N. Gruden, Archives of toxicology 37, 149-154 (1977).

25. K.B. Jacobson, J.E. Turner, Toxicology 16(1), 1-37 (1980) 